Document downloaded from:

http://hdl.handle.net/10251/59021

This paper must be cited as:

Penaranda-Foix, FL.; Janezic, MD.; Catalá Civera, JM.; Canós Marín, AJ. (2012). Full-wave analysis of dielectric-loaded cylindrical waveguides and cavities using a new four-port ring network. IEEE Transactions on Microwave Theory and Techniques. 60(9):2730-2740. doi:10.1109/TMTT.2012.2206048.

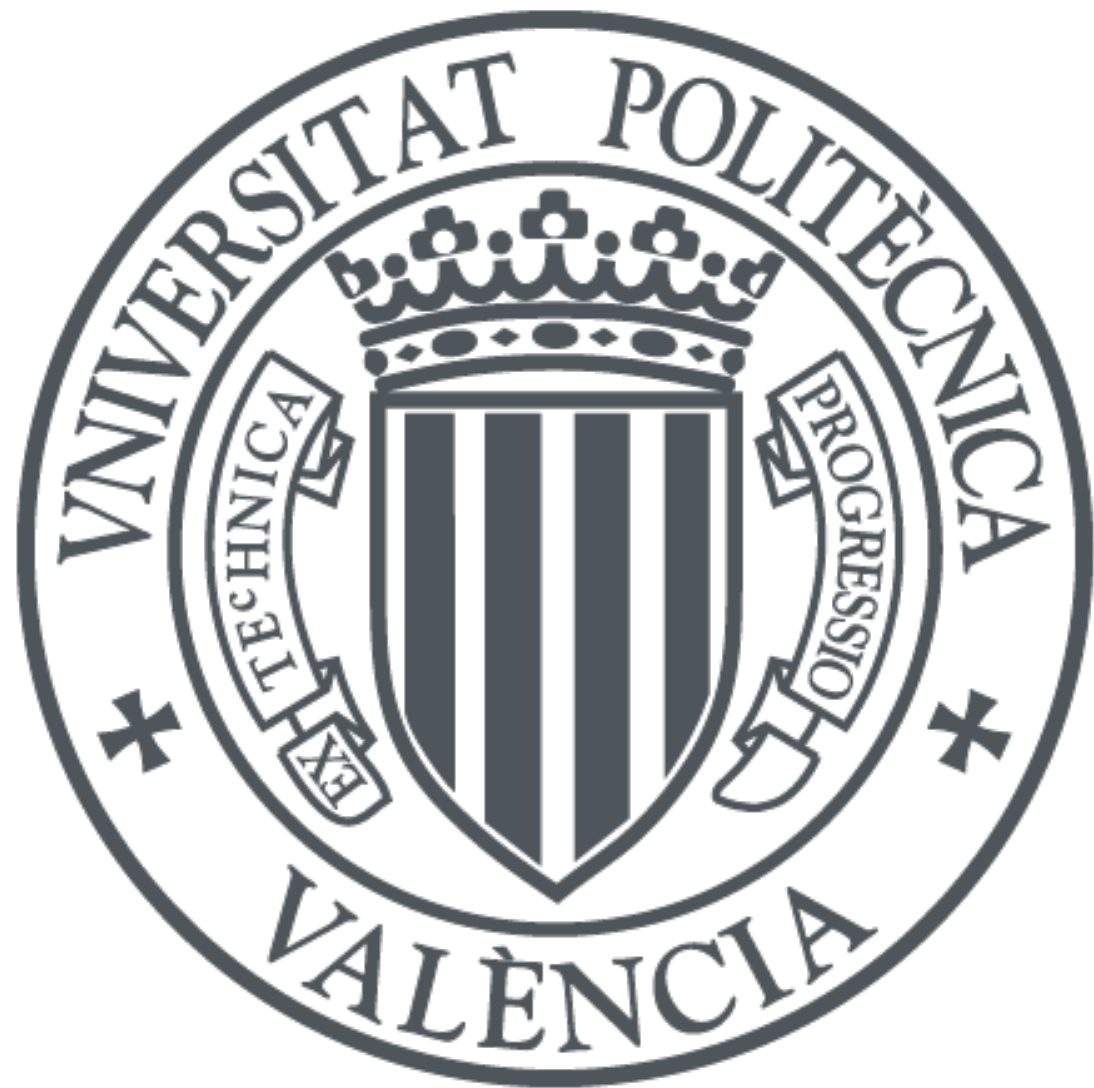

The final publication is available at

http://dx.doi.org/10.1109/TMTT.2012.2206048

Copyright Institute of Electrical and Electronics Engineers (IEEE)

Additional Information

"(C) 2012 IEEE. Personal use of this material is permitted. Permission from IEEE must be obtained for all other uses, in any current or future media, including reprinting/republishing this material for advertising or promotional purposes, creating new collective works, for resale or redistribution to servers or lists, or reuse of any copyrighted component of this work in other works." 


\title{
Full-Wave Analysis of Dielectric-Loaded Cylindrical Waveguides and Cavities Using a New Four-Port Ring Network
}

\author{
Felipe L. Penaranda-Foix, Member, IEEE, Michael D. Janezic, Senior Member, IEEE, Jose M. Catala- \\ Civera, Member, IEEE, and Antoni J. Canos
}

\begin{abstract}
In this paper, a full-wave method for the electromagnetic analysis of dielectric-loaded cylindrical and coaxial waveguides and cavities is developed. For this purpose, a new 4-port ring network is proposed, and the mode-matching method is applied to calculate the Generalized Admittance Matrix (GAM) of this new structure. A number of analyses on dielectric-loaded waveguide structures and cavities have been conducted in order to validate and to assess the accuracy of the new approach. The results have been compared with theoretical values, numerical modeling from the literature, and data from commercial electromagnetic simulators. The method has been also applied to the accurate determination of dielectric properties, and we provide an example of these measurements as another way to validate this new method.
\end{abstract}

Index Terms-Electromagnetic modeling, dielectric resonator, microwave filter, mode-matching, circuit analysis, dielectricloaded waveguides, dielectric measurements.

\section{INTRODUCTION}

$\mathrm{D}$ ielectric-loaded waveguides and cavities are increasingly being employed in passive devices, such as microwave filters or dielectric resonators, that are integrated into satellite and mobile communications systems because of their small size, low loss, and temperature stability [1]. Dielectric materials also have many important functions in the microelectronics industry. For example, new packaging technologies require substrates with low permittivity. Highpermittivity materials are used to reduce the dimensions of circuits at lower frequencies. Other important new areas of applications include microwave heating [2] and sensors [3-5].

This broad range of microwave applications demands a detailed knowledge of the dielectric properties of materials, including solids, liquids, emulsions and powders [6-10]. As electrical components are miniaturized, the need for wellcharacterized dielectric measurements on materials increases

Manuscript received December, 2011.

Felipe L. Penaranda-Foix, Jose M. Catala-Civera and Antoni J. Canos are with Instituto ITACA, Universidad Politécnica de Valencia, Camino de Vera, $\mathrm{s} / \mathrm{n}$, 46022-Valencia, Spain (Felipe L. Penaranda-Foix, the corresponding author, phone: +34-96 387 9711; e-mail: fpenaran@dcom.upv.es).

Michael D. Janezic is with the National Institute of Standards and Technology-NIST 325 Broadway, MS 818.01; Boulder, CO 80305 USA.
$[11,12]$. Dielectric properties measurement strategies include waveguide cells (in reflection or/and transmission), resonators and free-space methods [13-16]. Dielectric-loaded cylindrical waveguides and cavities can provide new and accurate dielectric measurement procedures to be applied under these methodologies [17-20].

As a consequence, the study of dielectric inhomogeneities in waveguides and cavities has been a main task of microwave researchers over the last decades. The technical literature offers a large number of papers about the numerical solutions of the eigenmodes and eigenvectors of canonical metallic cavities loaded with dielectric resonators. The finite-element method (FEM) [21] and finite-difference time-domain (FDTD) [22] procedures have been primarily employed to solve this problem. The need to employ refined 3D meshes, and the frequency dependence of calculations, make these methods very demanding in terms of computation time and memory resources.

To overcome these limitations, the Mode-Matching (MM) method [23-26] has emerged as an efficient and accurate technique to solve waveguide discontinuities and cavities. The boundary integral-resonant-mode expansion (BI-RME) technique $[27,28]$ has also been efficiently applied to the analysis of dielectric-loaded cavities of rectangular shape. For complex or large size waveguides or cavities, however, the MM method may suffer from convergence problems, and it has been combined with other analytical techniques [29-32]. Circuit analysis and segmentation have also proved to be powerful tools for analyzing complex dielectric-filled structures [33-35]. The generalized circuital analysis is a method for solving electromagnetic problems that consists of the segmentation of the whole geometry of the microwave structure into simpler elements, which then can be solved in an easier way [25, 36-41]. Once the simpler structures have been solved separately, they can be joined or combined through the use of the Generalized Admittance Matrix (GAM) in order to give the complete solution of the complex structure.

In this paper, the calculation of the GAM matrix of a new 4-port dielectric ring network is proposed. The term 4-port does not refer to the terminals of the entire structure that is being analyzed. As shown in Figure 2, this 4-port ring 


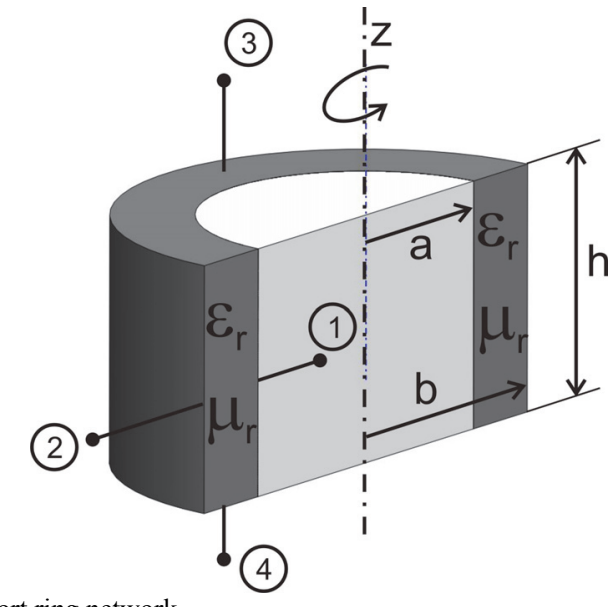

Fig. 1. 4-port ring network.

network is only one of the elements, used in conjunction with other circuit elements, to model the larger structure. A 4-port dielectric ring network is necessary because of the multiple dielectric layers that can occur in both the radial (ports 1 and 2) and axial (ports 3 and 4) directions, as shown in Figure 1. The GAM will be computed using the MM method, where the field in each port is approximated by a series expansion of basis functions. The set of basis functions has been chosen so that one can solve the resulting integrals analytically, without having to employ numerical methods. The combination of this new network with other circuit elements, such as cylindrical or coaxial waveguides, will allow an efficient and accurate tool to the full-wave solution of the scattering matrix or the resonant frequencies of dielectric-loaded cylindrical structures. Dielectric resonator filters and dielectric-filled reentrant coaxial waveguides and cavities can be solved straightforwardly with the use of the developed full-wave analysis method. Moreover, the use of microwave cavities partially filled with two dielectrics shows a clear application of the method for measuring the dielectric properties of materials $[42,43]$.

The validity of the proposed 4-port dielectric ring network is examined by modeling different well-known cylindrical transmission-line and cavity structures and then comparing the results with those included in the technical literature as well as with those given by other numerical techniques. Measurements of some microwave devices are also included for validation purposes.

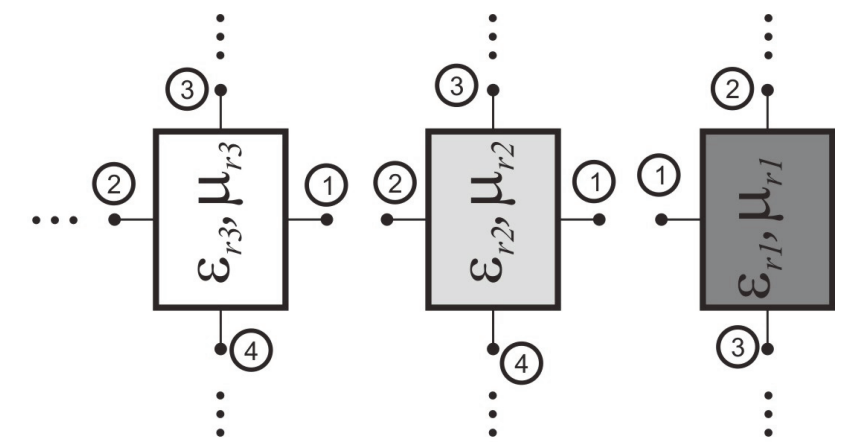

Fig. 2. Example of several 4-port and 3-port interconnection networks to model a multilayer structure.

\section{THEORY}

Figure 1 shows the proposed 4-port network to be analyzed. It consists of a toroid with inner radius $a$, outer radius $b$, and height $h$, with permittivity $\varepsilon_{r}\left(\varepsilon_{r}=\varepsilon^{\prime}-\mathrm{j} \cdot \varepsilon^{\prime \prime}\right)$ and permeability $\mu_{r}$ $\left(\mu_{r}=\mu^{\prime}-\mathrm{j} \cdot \mu^{\prime \prime}\right)$. The four ports are defined as follows: port 1 at $r=a, 0 \leq z \leq h$, port 2 at $r=b, 0 \leq z \leq h$, port 3 at $a \leq r \leq b, z=h$ and port 4 at $a \leq r \leq b, z=0$.

The 4-port network can be combined with other networks by circuit analysis to model more complex structures. As an example, Figure 2 shows how this 4-port network can be interconnected to other 3-port networks [44] to model a multilayer structure composed of several dielectric materials. The proposed circuit analysis enables the calculation of either the scattering parameters, in the case of a transmission-line structure, or the resonant frequencies for cavities or resonators.

The GAM of a 4-port network is defined by the general expression (1):

$$
\mathbf{Y}=\left(\begin{array}{llll}
\mathbf{Y}_{11} & \mathbf{Y}_{12} & \mathbf{Y}_{13} & \mathbf{Y}_{14} \\
\mathbf{Y}_{21} & \mathbf{Y}_{22} & \mathbf{Y}_{23} & \mathbf{Y}_{24} \\
\mathbf{Y}_{31} & \mathbf{Y}_{32} & \mathbf{Y}_{33} & \mathbf{Y}_{34} \\
\mathbf{Y}_{41} & \mathbf{Y}_{42} & \mathbf{Y}_{43} & \mathbf{Y}_{44}
\end{array}\right)
$$

It is important to note that each element in the GAM is a matrix that relates the modes in one port to the modes in remaining ports $[26,45,46]$.

In general, the elements in (1) represent TEM, TM or TE modes. However, the analysis described here is restricted to the TM modes with symmetry of revolution $\left(\mathrm{TM}_{0 \mathrm{n}}\right)$. Therefore, because of the particular geometry of the structures defined in Fig. 1, only TEM and TM modes are taken into account in the model. This restriction is strictly due to the type of the structures we are interested in, and it does not represent a loss of generality of the GAM technique. The procedure is in fact similar to the one followed in [47], where only $\mathrm{TE}_{0 \mathrm{np}}$ modes were employed to analyze the split post dielectric resonator.

With these assumptions, we define the components of the electromagnetic fields in the inner region $(a \leq r \leq b)$ as [48]:

$$
\begin{gathered}
E_{z}=\sum_{n=0}^{\infty} f_{0 n}(r)\left(a_{n} e^{-\gamma_{n} z}+b_{n} e^{+\gamma_{n} z}\right) \\
E_{r}=\sum_{n=0}^{\infty} \frac{-\gamma_{n}}{k_{c 0 n}} \cdot f_{0 n}^{\prime}(r)\left(a_{n} e^{-\gamma_{n} z}-b_{n} e^{+\gamma_{n} \cdot z}\right) \\
H_{\varphi}=\sum_{n=0}^{\infty} \frac{-j \omega \varepsilon_{0} \varepsilon_{r}}{k_{c 0 n}} f_{0 n}^{\prime}(r)\left(a_{n} e^{-\gamma_{n} z}+b_{n} e^{+\gamma_{n} z}\right)
\end{gathered}
$$

where $f_{0 n}(r)$ and $f_{0 n}^{\prime}(r)$ are: 


$$
\begin{aligned}
& f_{0 n}(r)=\left\{\begin{array}{c}
0, n=0 \\
\mathrm{~J}_{0}\left(k_{c 0 n} r\right)+\Gamma_{n} \mathrm{Y}_{0}\left(k_{c 0 n} r\right), n>0 \\
-1 /\left(r \gamma_{0}\right), n=0
\end{array}\right. \\
& f_{0 n}^{\prime}(r)=\left\{\begin{array}{c}
\left(\mathrm{J}_{1}\left(k_{c 0 n} r\right)-\Gamma_{n} \mathrm{Y}_{1}\left(k_{c 0 n} r\right), n>0\right.
\end{array}\right.
\end{aligned}
$$

In (3), the values of $k_{c 0 n}$ (cut-off wave number) depend on the boundary conditions and the value of $\Gamma_{n}$. The mode $n=0$ corresponds to the TEM mode, where $\left.k_{c 0 n}\right|_{n=0}=0$. However, in order to define (2) and (3) with more generality, and to include TEM mode, the criteria of $k_{c 00}=1$ is adopted hereinafter.

The propagation constant $\gamma_{n}$ and the cut-off wave number $k_{c 0 n}$ are related as follows:

$$
k_{c 0 n}^{2}=k^{2}+\gamma_{n}^{2}
$$

where $k$ is the free-space wave number $k=\omega \sqrt{\varepsilon \mu}$.

The functions $\mathrm{J}_{n}($.$) and \mathrm{Y}_{n}($.$) in (3) are, respectively, the$ Bessel functions of the first and second kind with order $n(0$ or 1), and $\Gamma_{n}$ is a coefficient that depends on the boundary conditions.

The next subsection describes the calculation of the set of parameters $\mathbf{Y}_{i 1},(i=1,2,3,4)$ of (1).

\section{A. Parameters $\mathbf{Y}_{i 1}$}

To calculate the $\mathbf{Y}_{i 1}$ parameters, electric wall conditions are imposed on ports 2, 3 and 4, therefore, fields in (2) become:

$$
\left\{\begin{array} { l } 
{ E _ { r } | _ { z = 0 } = 0 } \\
{ E _ { r } | _ { z = h } = 0 } \\
{ E _ { z } | _ { r = b } = 0 }
\end{array} \Rightarrow \left\{\begin{array}{c}
a_{n}=b_{n} \\
\gamma_{n}=j \frac{n \pi}{h} \\
\Gamma_{n}=-\mathrm{J}_{0}\left(k_{c 0 n} b\right) / \mathrm{Y}_{0}\left(k_{c 0 n} b\right)
\end{array}\right.\right.
$$

By substituting the above relations in (2), the electromagnetic fields in the inner region are:

$$
\begin{gathered}
E_{z}=\sum_{n=0}^{\infty} 2 a_{n} f_{0 n}(r) \cosh \left(\gamma_{n} z\right) \\
E_{r}=\sum_{n=0}^{\infty} 2 a_{n} \frac{\gamma_{n}}{k_{c 0 n}} f_{0 n}^{\prime}(r) \sinh \left(\gamma_{n} z\right) \\
H_{\varphi}=\sum_{n=0}^{\infty} 2 a_{n} \frac{-j \omega \varepsilon_{0} \varepsilon_{r}}{k_{c 0 n}} f_{0 n}^{\prime}(r) \cosh \left(\gamma_{n} z\right)
\end{gathered}
$$

Given the propagation constant $\gamma_{n}$, the value of the cut-off wave numbers can be calculated as:

$$
k_{c 0 n}^{2}=k^{2}+\gamma_{n}^{2}=k^{2}-\left(\frac{n \pi}{h}\right)^{2}
$$

In this case, the TEM mode does not exist because of the resulting geometry when short-circuiting ports 2,3 and 4 . However, it must be noted that when computing the $\mathbf{Y}_{i 3}$ and $\mathbf{Y}_{i 4}$ parameters, the TEM mode does exist and thus it must be included.

The incident electric field at port 1 is:

$$
E_{z}=\sum_{m=0}^{\infty} \alpha_{m} \sin \left(2 \pi m \frac{z}{h}\right)+\beta_{m} \cos \left(2 \pi m \frac{z}{h}\right)
$$

where we assume a Fourier series expansion, based on trigonometric basis functions, for this port.

Next, we equate (8) and the $E_{z}$ field in (6) at $r=a$, and calculate the amplitudes $a_{n}$ using the orthogonal properties of the trigonometric functions. We then obtain :

$$
a_{n}=\frac{\chi_{n}}{h f_{0 n}(a)} \sum_{m=0}^{\infty} \alpha_{m} \cdot I_{m n}^{(s)}+\beta_{m} \cdot I_{m n}^{(c)}
$$

where $I_{m n}^{(s)}, I_{m n}^{(c)}$ and $\chi_{n}$ are defined in Appendix, section A.

\section{Parameter $\mathbf{Y}_{11}$}

In (10) the magnetic field at port 1 is written as a series expansion similar to the incident electric field defined in (8):

$$
H_{\varphi}=\sum_{q=0}^{\infty} c_{q} \sin \left(2 \pi q \frac{z}{h}\right)+d_{q} \cos \left(2 \pi q \frac{z}{h}\right)
$$

The magnetic field at port 1 and the inner magnetic field from (6) must be equal at $r=a$, which leads to the following expressions:

$$
\begin{gathered}
\sum_{q=0}^{\infty} c_{q} \sin \left(2 \pi q \frac{z}{h}\right)+d_{q} \cos \left(2 \pi q \frac{z}{h}\right)= \\
=\sum_{n=0}^{\infty} 2 a_{n} \frac{-j \omega \varepsilon_{0} \varepsilon_{r}}{k_{c 0 n}} f_{0 n}^{\prime}(a) \cosh \left(\gamma_{n} z\right) \\
c_{q}=\frac{2}{h} \sum_{n=0}^{\infty} 2 a_{n} \frac{-j \omega \varepsilon_{0} \varepsilon_{r}}{k_{c 0 n}} f_{0 n}^{\prime}(a) I_{q n}^{(s)} \\
d_{q}=\frac{2 \chi_{q}}{h} \sum_{n=0}^{\infty} 2 a_{n} \frac{-j \omega \varepsilon_{0} \varepsilon_{r}}{k_{c 0 n}} f_{0 n}^{\prime}(a) I_{q n}^{(c)}
\end{gathered}
$$

Since parameter $\mathbf{Y}_{11}$ is defined as the relation between the electric and magnetic fields at port 1 , we have:

$$
\mathbf{h}_{1}=\left(\begin{array}{l}
\mathbf{c} \\
\mathbf{d}
\end{array}\right)=\mathbf{Y}_{11} \cdot \mathbf{e}_{1}=\left(\begin{array}{cc}
\mathbf{Y}_{11}^{(s s)} & \mathbf{Y}_{11}^{(s c)} \\
\mathbf{Y}_{11}^{(c s)} & \mathbf{Y}_{11}^{(c c)}
\end{array}\right) \cdot\left(\begin{array}{l}
\boldsymbol{\alpha} \\
\boldsymbol{\beta}
\end{array}\right)
$$

where each submatrix $\mathbf{Y}_{11}^{(x y)}$, being $(x, y) \in(s, c)$, is derived from (11) as follows:

$$
\left.Y_{11}^{(s s)}\right|_{q m}=\frac{2}{h} \sum_{n=0}^{\infty} \frac{-j \omega \varepsilon_{0} \varepsilon_{r}}{k_{c 0 n}} \frac{f_{0 n}^{\prime}(a)}{f_{0 n}(a)} 2 \chi_{n} \frac{I_{m n}^{(s)}}{h} I_{q n}^{(c)}
$$




$$
\begin{gathered}
\left.Y_{11}^{(s c)}\right|_{q m}=0 \\
\left.Y_{11}^{(c s)}\right|_{q m}=0 \\
\left.Y_{11}^{(c c)}\right|_{q m}=\frac{2 \chi_{q}}{h} \sum_{n=0}^{\infty} \frac{-j \omega \varepsilon_{0} \varepsilon_{r}}{k_{c 0 n}} \frac{f_{0 n}^{\prime}(a)}{f_{0 n}(a)} 2 \chi_{n} \frac{I_{m n}^{(c)}}{h} I_{q n}^{(c)}
\end{gathered}
$$

\section{Parameter $\mathbf{Y}_{21}$}

The calculation of parameter $\mathbf{Y}_{21}$ is obtained in a similar way to the $\mathbf{Y}_{11}$ parameter, noting that port 2 is now placed at $r=b$.

\section{Parameter $\mathbf{Y}_{31}$}

The magnetic field at port 3 is written as a series expansion of the basis functions $h_{q}^{(3)}(r)$ :

$$
H_{\varphi}=\sum_{q=0}^{\infty} c_{q} h_{q}^{(3)}(r)=\sum_{q=0}^{\infty} c_{q} \omega_{1 q}^{(3)}(r) N_{q}^{(e 3)}, a \leq r \leq b
$$

where the basis functions $h_{q}^{(3)}(r)$ used at port 3 and at port 4 are orthogonal in the range $a \leq r \leq b$. They are a complete set of Bessel functions, which makes them suitable for structures that can be described in circular-cylindrical coordinates. The series expansion used is a generalization of the Dini series expansions [49] as they were developed in [50]. This series expansion is included in Appendix, section B (superindex ${ }^{(3)}$ in function $\omega_{1 q}^{(3)}(r)$ refers to port 3). The term $N_{q}^{(e 3)}$ is a normalization term for the electric field [51, 52]. This term is also calculated in Appendix, section C.

By equating the magnetic field at port 3 with the inner magnetic field, defined in (6), over the region $z=h$, we get:

$$
\begin{gathered}
\sum_{q=0}^{\infty} c_{q} \omega_{1 q}^{(3)}(r) N_{q}^{(e 3)}= \\
=\sum_{n=0}^{\infty} 2 a_{n} \frac{-j \omega \varepsilon_{0} \varepsilon_{r}}{k_{c 0 n}} f_{0 n}^{\prime}(r) \cosh \left(\gamma_{n} h\right) \\
\Downarrow \\
c_{q}=\frac{1}{B_{q}^{(3)} N_{q}^{(e 3)}} \sum_{n=0}^{\infty} 2 a_{n} \frac{-j \omega \varepsilon_{0} \varepsilon_{r}}{k_{c 0 n}} \cos (n \cdot \pi) I_{q n}^{(\omega)}
\end{gathered}
$$

where $N_{q}^{(e 3)}$ has been defined in (37) and $B_{q}^{(3)}$ in (34) and $I_{q n}^{(\omega)}$ is defined in Appendix, section D.

Defining the parameter $\mathbf{Y}_{31}$ as the relation between the magnetic field at port 3 and electric field at port 1, we have:

$$
\mathbf{h}_{3}=\mathbf{c}=\mathbf{Y}_{31} \cdot \mathbf{e}_{1}=\left(\begin{array}{ll}
\mathbf{Y}_{31}^{(s)} & \mathbf{Y}_{31}^{(c)}
\end{array}\right) \cdot\left(\begin{array}{l}
\boldsymbol{\alpha} \\
\boldsymbol{\beta}
\end{array}\right)
$$

where each submatrix $\mathbf{Y}_{31}^{(x)}$, being $(x) \in(s, c)$ is from (15):

$$
\begin{gathered}
\left.Y_{31}^{(s)}\right|_{q m}=\frac{1}{B_{q}^{(3)} N_{q}^{(e 3)}} \cdot \\
\cdot \sum_{n=0}^{\infty} \frac{-j \omega \varepsilon_{0} \varepsilon_{r}}{k_{c 0 n}} 2 \chi_{n} \frac{\cos (n \pi)}{f_{0 n}(a)} \frac{I_{m n}^{(s)}}{h} I_{q n}^{(\omega)} \\
\left.Y_{31}^{(c)}\right|_{q m}=\frac{1}{B_{q}^{(3)} N_{q}^{(e 3)}} \cdot \\
\cdot \sum_{n=0}^{\infty} \frac{-j \omega \varepsilon_{0} \varepsilon_{r}}{k_{c 0 n}} 2 \chi_{n} \frac{\cos (n \pi)}{f_{0 n}(a)} \frac{I_{m n}^{(c)}}{h} I_{q n}^{(\omega)}
\end{gathered}
$$

\section{Parameter $\mathbf{Y}_{41}$}

The calculation of parameter $\mathbf{Y}_{41}$ is obtained in a similar manner to the $\mathbf{Y}_{31}$ parameter, but in the region $z=0$.

\section{B. Parameters $\mathbf{Y}_{i 2}, \mathbf{Y}_{i 3}$ and $\mathbf{Y}_{i 4}$}

Since the remaining parameters of columns 2, 3 and 4 of the $Y$-matrix are calculated in a similar way to the parameters in the first column, $Y_{i l}$, we do not include here (for the sake of space) how their expressions are determined.

\section{Losses in the Electric walls}

Dielectric or magnetic losses of the material in the ring circuit of Figure 1 are included in the imaginary parts of the complex permittivity and complex permeability respectively, as defined in previous paragraphs, but the conductive losses associated with the electric walls requires an additional explanation. The impedance associated with a finite conductivity electric wall can be calculated with the wellknown expression [53- 55]:

$$
Z_{\text {short }} \approx R_{s}(1+j), R_{s}=\frac{1}{\sigma \delta}=\sqrt{\frac{\pi f \mu}{\sigma}}
$$

The same expression can be retrieved from the computed GAM matrix. Assuming $b \rightarrow \infty$, we obtain a 1-port element where the unique GAM parameter is $\mathbf{Y}_{11}$. From the second Maxwell equation, a good dielectric satisfies $\sigma /(\omega \varepsilon)<<1$ and a good conductor satisfies $\sigma /(\omega \varepsilon)>>1$ (see [48, 56]). Thus, for a good conductor, we can assume that the following permittivity relationship applies:

$$
\varepsilon=\frac{-j \sigma}{\omega}
$$

The open space wave number $k$ associated with this permittivity is:

$$
k^{2}=\omega^{2} \mu \varepsilon=-j \omega \mu \sigma \quad \Rightarrow \quad k=\frac{1+j}{\delta}
$$

where $\delta$ is the penetration depth used in (18). Using (20) in parameter $\mathbf{Y}_{l l}$, we obtain the following expression: 


$$
\begin{gathered}
\frac{f_{0 n}^{\prime}(a)}{f_{0 n}(a)}=\left.\frac{-\mathrm{J}_{1}\left(k_{c 0 n} a\right)-\frac{\mathrm{J}_{0}\left(k_{c 0 n} b\right)}{\mathrm{Y}_{0}\left(k_{c 0 n} b\right)} \mathrm{Y}_{1}\left(k_{c 0 n} a\right)}{\mathrm{J}_{0}\left(k_{c 0 n} a\right)+\frac{\mathrm{J}_{0}\left(k_{c 0 n} b\right)}{\mathrm{Y}_{0}\left(k_{c 0 n} b\right)} \mathrm{Y}_{0}\left(k_{c 0 n} a\right)}\right|_{b \rightarrow \infty} \approx \\
\approx-\frac{\mathrm{H}_{1}^{(2)}\left(k_{c 0 n} a\right)}{\mathrm{H}_{0}^{(2)}\left(k_{c 0 n} a\right)}
\end{gathered}
$$

where the cut-off wave number $k_{c 0 n}$ is (7):

$$
k_{c 0 n}^{2}=k^{2}+\gamma_{n}^{2}=\omega^{2} \mu \varepsilon-\left(\frac{n \pi}{h}\right)^{2}=-j \omega \mu \sigma-\left(\frac{n \pi}{h}\right)^{2}
$$

For most metals, the value of the conductivity $\sigma$ is relatively high, so the expression for the wave number can be approximated by:

$$
k_{c 0 n}^{2} \approx-j \omega \mu \sigma
$$

Then, with respect to $\mathbf{Y}_{11}$ we have:

$$
\begin{gathered}
\left.Y_{11}^{(s s)}\right|_{q m} \approx \frac{-1}{1+j} \frac{1}{R_{s}} \delta(m-q) \\
\left.Y_{11}^{(s c)}\right|_{q m}=0 \\
\left.Y_{11}^{(c s)}\right|_{q m}=0 \\
\left.Y_{11}^{(c c)}\right|_{q m} \approx \frac{-1}{1+j} \frac{1}{R_{s}} \delta(m-q)
\end{gathered}
$$

where $\delta($.$) is the Dirac delta function. As expected, the 1-$

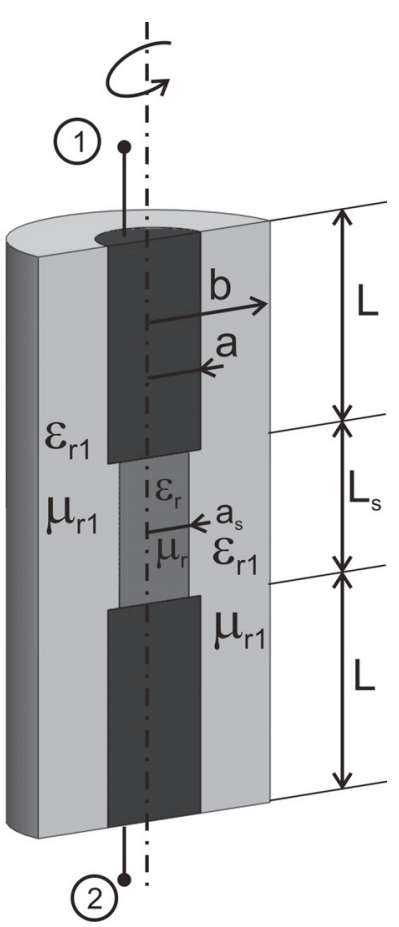

(a)

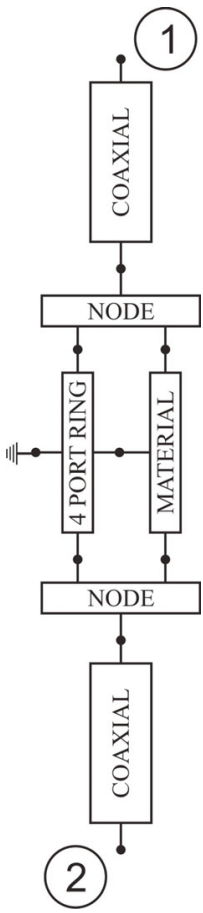

(b)
Fig. 3. Re-entrant coaxial waveguide and its circuit segmentation.

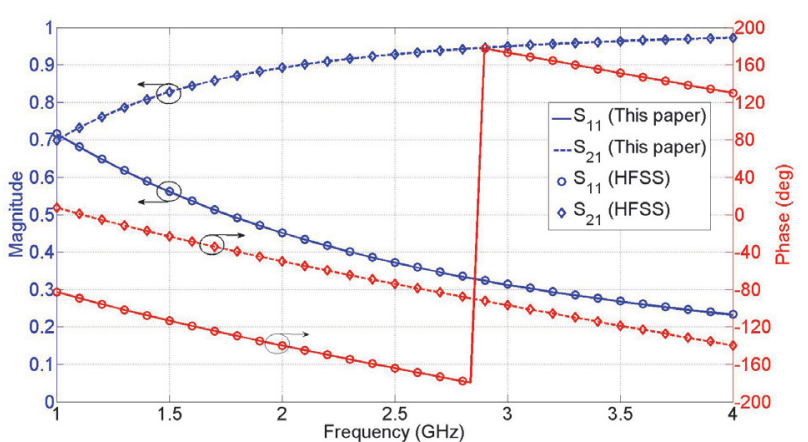

Fig. 4. Magnitude and phase of the $\mathrm{S}$ parameters with air gap when $a=7.25 \mathrm{~mm}, b=24.9 \mathrm{~mm}, a_{s}=10 \mathrm{~mm}, L_{s}=2 \mathrm{~mm}, L=15 \mathrm{~mm}$ and $\varepsilon_{r}=1$.

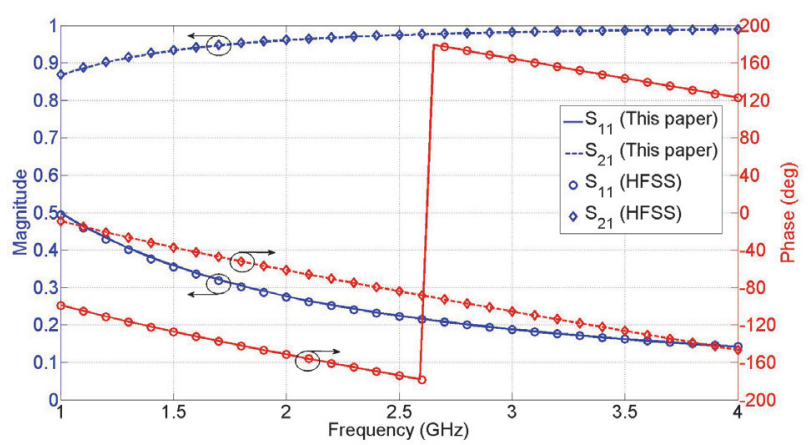

Fig. 5. Magnitude and phase of the $\mathrm{S}$ parameters with air gap when $a=7.25 \mathrm{~mm}, b=24.9 \mathrm{~mm}, a_{s}=10 \mathrm{~mm}, L_{s}=2 \mathrm{~mm}, L=15 \mathrm{~mm}$ and $\varepsilon_{r}=2-j \cdot 0.002$.

port network GAM for the finite conductive electric wall results in a diagonal matrix with the impedance value of (18). The sign discrepancy comes from the Poynting vector flux that in the present paper is outgoing from the network and not ingoing as usual. Applying this standard criterion, the sign of the magnetic field changes, which also changes the the sign of the GAM, leading to the same value for (18).

\section{NumERICAL RESULTS AND DisCUSSION}

In order to validate the accuracy of the numerical model described in the previous section, and demonstrate the usefulness of the combination of this new 4-port network with cylindrical or coaxial waveguides, modeling results of typical dielectric-loaded microwave structures are compared with analytical expressions, general-purpose FEM simulators and with results previously published in the literature. This is shown in sections III.A, III.B, III.C and III.D. Section III.E includes an example of permittivity measurements as illustrative of another application of the proposed network.

\section{A. Coaxial waveguide loaded with a dielectric disk}

Fig. 3-(a) shows a coaxial waveguide with a cylindrical dielectric sample positioned between the two inner conductors. Figure 3-(b) shows how this structure is broken down into different networks, where the proposed 4-port ring network is combined with 1-port (short-circuit), 2-port (coaxial line), and 3-port (node) networks (see [33, 44] for details of this networks). 


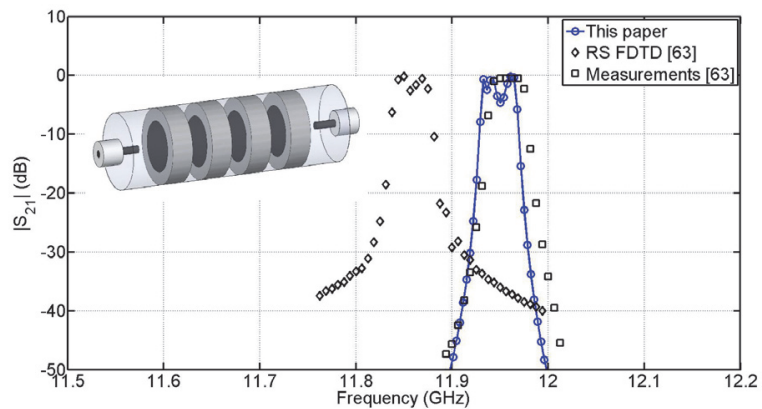

Fig. 6. 4-pole $\mathrm{TM}_{01}$ Dielectric Resonator Filter (see dimensions in [63]).

Figs. 4 and 5 show the magnitude and phase of the Sparameters of the 2-port structure calculated by joining the nodes and networks described in Figure 3-(b) for a dielectric disc of permittivity of air and permittivity of $\varepsilon_{r}=2-j \cdot 0.002$, respectively. Dimensions of the geometry are given in the figure caption. Only 15 modes over 50 frequency points were required to solve the dielectric-loaded coaxial in less than 6 seconds with a PC (Intel Core i5-2320 and 6 GB RAM). The computed results (labeled MODAL) are in very good agreement with those provided by the commercial code Ansoft HFSS (labeled HFSS) also included in the Figures for comparison. Of course, the accuracy of the modeling depends on the number of modes selected to perform the calculations. The number of modes has a direct impact on the required processing time. In this, and in the rest of the simulated cases, good accuracy has been reached, when compared with references in the literature, by selecting only a few modes (i.e. 15 modes in this first example), which allows one to analyze the structures in a reasonable amount of time.

By short-circuiting (perfect electric walls are assumed in the simulation) both ends (ports 1 and 2), and imposing resonant condition [57], this structure becomes a re-entrant cavity, which is a common device for measuring the complex permittivity of dielectric materials, as described in [29, 58-62].

\section{B. Cylindrical Dielectric Resonant (DR) Filters}

The second structure considered is a 4-pole $\mathrm{TM}_{01}$ Dielectric Resonator (DR) filter shown in Figure 6 [63]. It consists of a set of spaced dielectric-loaded cylindrical waveguides coupled by coaxial lines. The dielectric support of the dielectric resonator has a relative permittivity of 1.031 , and the rest of parameters are given in the figure caption. To solve for the S-parameters of this structure, the schematic of Figure 6 is segmented by connecting the nodes of the 4-port network to cylindrical waveguides in a similar manner to the coaxial of Figure 3.

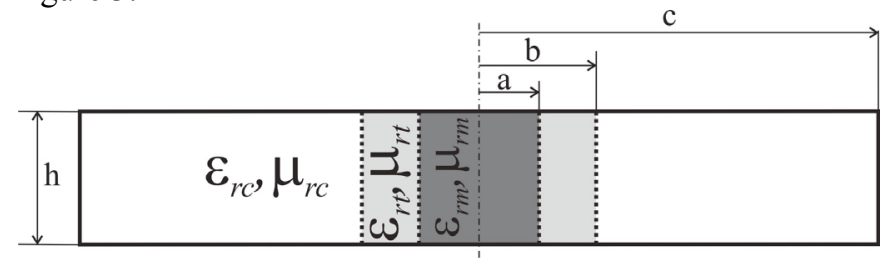

Fig. 7. Coaxially loaded cavity with container.

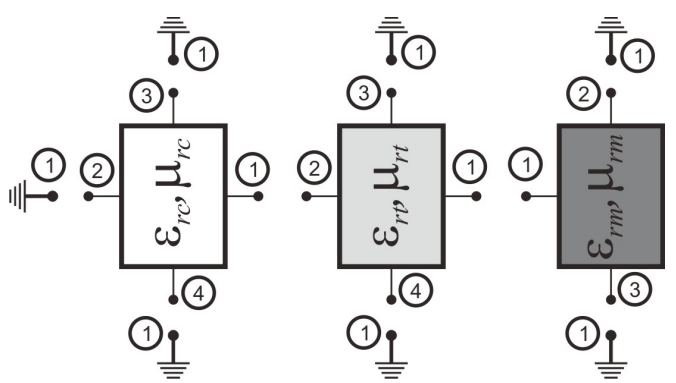

Fig. 8. Circuit segmentation of a coaxially loaded cavity.

The computed S-parameters for the 4-pole filter are shown in Figure 6. To obtain an accurate S-parameters over 150 frequency points, we included 30 modes, which resulted in a total computation time of 60 seconds using a laptop (Intel Core i5 and 6 GB RAM). The computed performance of the 4pole filter is compared in Figure 6 with simulations and measurements of the same structure carried out in [63]. Very good agreement with measurements is observed from the figure.

\section{Cylindrical cavity coaxially-loaded with two dielectric materials}

The third structure to be studied with the proposed method is a cylindrical cavity coaxially-loaded with two dielectric materials that extends along the cavity height, as shown in Figure 7. This inhomogeneous cavity can be solved analytically, giving us the opportunity to compare the accuracy of the proposed model with previously-published analytical results. For this configuration, ports 1 and 2 of the 4-port network are joined with the materials in contact, whereas ports 3 and 4 are short-circuited (see Figure 8). The 3 -port network of Fig. 8 is described in [44]. Short-circuits can be modeled either as perfect conductors (PEC) or conductors with a finite conductivity, as described previously in the Theory section. Resonant frequencies and quality factors have been calculated using the resonant condition [57] and the complex resonant frequency concept [56].

Table I shows the first two resonant frequencies and Qfactors corresponding to the $\mathrm{TM}_{0 \mathrm{np}}\left(\mathrm{TM}_{010}\right.$ and $\left.\mathrm{TM}_{020}\right)$ modes

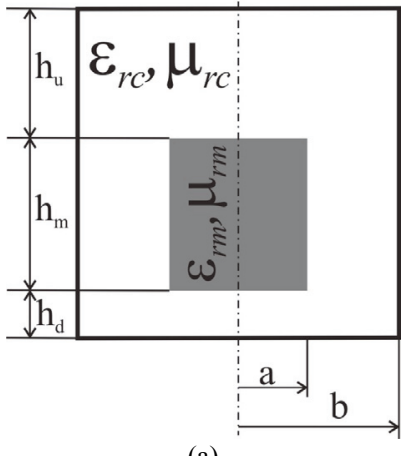

(a)

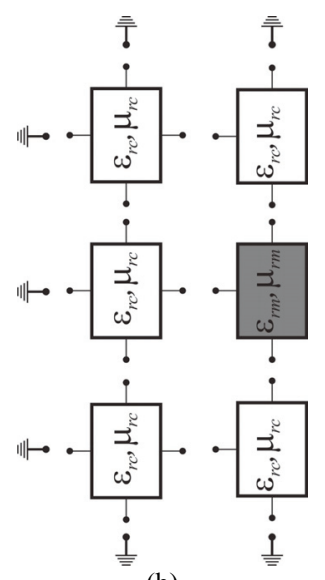

(b)
Fig. 9. Cylindrical cavity partially loaded with a dielectric disk (a) and circuit segmentation (b). 


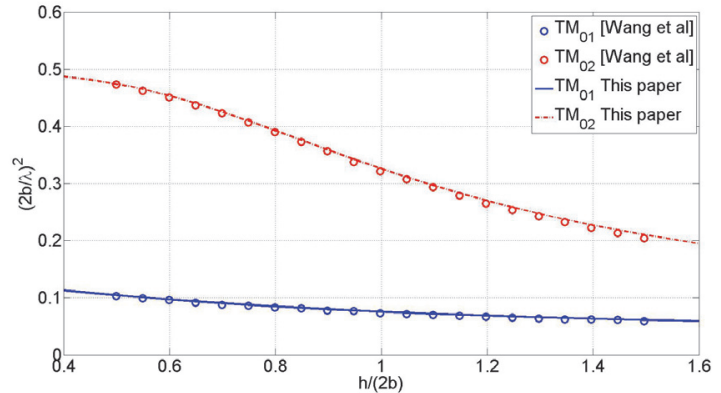

Fig. 10. Resonant frequency of the first $2 \mathrm{TM}$ modes, with $a / b=0.3, a=20$ $m m, h_{m} / h=0.9$ and $\varepsilon_{r}=36$.

of a cylindrical cavity coaxially-loaded with dielectric materials of different permittivity, and first resonant mode $\mathrm{TM}_{010}$ when the dielectric is inside a dielectric tube. In both cases (with and without tube), the calculated values are identical to those provided by an analytical solution of this structure [48] so that we can assess the accuracy and performance of this technique. In order to compare with the analytic solutions, the conductivity of the walls is assumed infinite $(\sigma=\infty)$. In all the cases the resonant frequencies provided by the Ansoft HFSS simulations are included, and the relative errors are about $1.3 \%$ in the resonant frequencies

TABLE I

RESONANT FREQUENCY COMPARISONS $a=15 \mathrm{~mm} ; b=20 \mathrm{~mm} ; c=50 \mathrm{~m} ; h=20 \mathrm{~mm}$

\begin{tabular}{|c|c|c|c|}
\hline & & $\mathrm{f}(\mathrm{GHz})$ & $\mathrm{Q}$ \\
\hline \multirow{3}{*}{$\begin{array}{c}\text { MODE } 1 \\
\varepsilon_{r m}=2 \cdot\left(1-\mathrm{j} \cdot 10^{-2}\right) \\
\varepsilon_{r t t}=2 \cdot\left(1-\mathrm{j} \cdot 10^{-2}\right)\end{array}$} & Analytic & 1.8736 & 144.536 \\
\hline & This paper & 1.8736 & 144.536 \\
\hline & HFSS & 1.8988 & 144.466 \\
\hline \multirow{3}{*}{$\begin{array}{c}\text { MODE } 2 \\
\varepsilon_{r m}=2 \cdot\left(1-\mathrm{j} \cdot 10^{-2}\right) \\
\varepsilon_{r t t}=2 \cdot\left(1-\mathrm{j} \cdot 10^{-2}\right)\end{array}$} & Analytic & 4.5788 & 265.069 \\
\hline & This paper & 4.5788 & 265.069 \\
\hline & HFSS & 4.6409 & 264.948 \\
\hline \multirow{3}{*}{$\begin{array}{c}\text { MODE } 1 \\
\varepsilon_{r m}=5 \cdot\left(1-\mathrm{j} \cdot 10^{-4}\right) \\
\varepsilon_{r t t}=5 \cdot\left(1-\mathrm{j} \cdot 10^{-4}\right)\end{array}$} & Analytic & 1.3020 & 11444.3 \\
\hline & This paper & 1.3020 & 11444.3 \\
\hline & HFSS & 1.3192 & 11442.2 \\
\hline \multirow{3}{*}{$\begin{array}{c}\text { MODE } 2 \\
\varepsilon_{r m}=5 \cdot\left(1-\mathrm{j} \cdot 10^{-4}\right) \\
\varepsilon_{r t t}=5 \cdot\left(1-\mathrm{j} \cdot 10^{-4}\right)\end{array}$} & Analytic & 3.7356 & 16965.3 \\
\hline & This paper & 3.7356 & 16965.3 \\
\hline & HFSS & 3.7857 & 19938.0 \\
\hline \multirow{3}{*}{$\begin{array}{c}\text { MODE } 1 \\
\varepsilon_{r m}=5 \cdot\left(1-\mathrm{j} \cdot 10^{-4}\right) \\
\varepsilon_{r t t}=2 \cdot\left(1-\mathrm{j} \cdot 10^{-2}\right)\end{array}$} & Analytic & 1.4322 & 698.79 \\
\hline & This paper & 1.4322 & 698.79 \\
\hline & HFSS & 1.4515 & 698.88 \\
\hline
\end{tabular}

TABLE II

SIMULATIONS OF RESONANT FREQUENCIES (IN GHZ) $\varepsilon_{r}=35.74 ; a=0.8636 \mathrm{~cm} ; b=1.295 \mathrm{~cm} ; h_{m}=0.762 \mathrm{~cm} ; h_{u}=h_{d}=0.381 \mathrm{~cm}$

\begin{tabular}{|c|c|c|c|c|}
\hline Mode & {$[1]$} & {$[65]$} & This paper & $\begin{array}{c}\text { Relative error (\%) } \\
\text { with [1] and [65] } \\
\text { respectively }\end{array}$ \\
\hline $\mathrm{TM}_{01}$ & 4.568 & 4.5442 & 4.5410 & $\begin{array}{c}0.60 \\
0.07\end{array}$ \\
\hline $\mathrm{TM}_{02}$ & 6.384 & 6.361 & 6.3732 & $\begin{array}{c}0.17 \\
-0.19\end{array}$ \\
\hline $\mathrm{TM}_{03}$ & 7.323 & 7.254 & 7.2622 & $\begin{array}{c}0.84 \\
-0.11\end{array}$ \\
\hline $\mathrm{TM}_{04}$ & 7.685 & 7.641 & 7.6614 & $\begin{array}{c}0.31 \\
-0.27\end{array}$ \\
\hline $\mathrm{TM}_{05}$ & 9.169 & 9.093 & 9.1078 & $\begin{array}{c}0.67 \\
-0.16\end{array}$ \\
\hline $\mathrm{TM}_{06}$ & 10.031 & 9.942 & 9.9827 & $\begin{array}{c}0.48 \\
-0.41\end{array}$ \\
\hline
\end{tabular}

and $0.05 \%$ in the quality factors.

\section{Cylindrical cavity partially loaded with a dielectric disk}

The next structure analyzed is a cylindrical cavity partiallyfilled with a dielectric disc that can be located at different height (see Figure 9-a). This cavity can be split into simple circuit elements, as shown in Figure 9-b, where the 4-port ring network is connected to the other 4-port ring networks (up and down) and terminated with short-circuits [44].

Figure 10 shows the calculated resonant frequencies of the first two modes $\left(\mathrm{TM}_{01}\right.$ and $\left.\mathrm{TM}_{02}\right)$ as a function of the rate between the cavity height and the dielectric disk diameter when the material is placed at the bottom $\left(h_{d}=0\right)$ and for a given value of permittivity (comb-line resonator). For comparison, the figure also reproduces the results given by [64] of the same structure, showing again very good agreement between both approaches.

The cavity loaded with the dielectric disk at the center $\left(h_{d}=h_{u}\right)$, as represented in Figure 9-(a), has been extensively used in the literature to compare different methods of analysis. Therefore, we compare our results with those obtained by the orthonormal basis method [1] and with the mode-matching method of [65]. Table II presents a list with some of these results corresponding to the $\mathrm{TM}_{0 \mathrm{n}}$ modes. Again, we find excellent agreement between our results and those using other approaches, which confirm the validity of the developed method (the conductivity is assumed to be infinite, because no information about it is provided in the references).

In order to compute each resonant frequency, the NelderMead minimization method was used [66], with an average of 180 evaluations when we included 30 modes, resulting in a computation time of 180 seconds per frequency point.

\section{E. Dielectric measurements with cylindrical cavity partially loaded with a dielectric disk}


Finally, we included an example of permittivity measurements of a dielectric disk in the cylindrical cavity depicted in Figure 9-(a), with $h_{d}=0$. Table III shows the measurements of the resonant frequency and Q-factor of the cylindrical cavity containing samples of ceramic materials (with high and low permittivity values) and the calculated permittivity of the samples using the circuital representation of Figure 9-(b). Resonance measurements have been carried out following the procedures described in [67]. Dimensions of cavity and samples are also given in the table, as well as the measured conductivity, which is determined through a measurement of the empty cavity.

The calculated results show very good agreement with the values provided by the material manufacturer's data sheet and with other measurements performed in a split-cylinder resonator at NIST, thereby confirming the validity of the developed approach to accurately measure the dielectric properties of materials.

\section{CONCLUSION}

In this paper, the GAM of a novel 4-port cylindrical ring network has been successfully solved. The combination of the proposed ring circuit network with coaxial and cylindrical waveguides can be used to model a variety of complex structures. For instance, they have been used for solving dielectric-loaded structures widely employed as microwave devices and resonators, including those with finite conductivity walls.

This new element has been used to calculate the Sparameters, resonant frequencies and quality factor of some dielectric loaded structures with dielectric disks.

The results provided by this new element have been compared with theoretical results, as well as with data included in the technical literature, with commercial FEM software values and with measurements, showing very good agreement in all cases.

APPENDIX

TABLE III

PERMITTIVITY MEASUREMENTS OF TRANS-TECH MATERIALS

$\mathrm{b}=49.07 \mathrm{~mm} ; \mathrm{h}_{\text {Total }}=20 \mathrm{~mm} ; \mathrm{h}_{\mathrm{d}}=0 \mathrm{~mm} ; \sigma=0.955 \cdot 10^{7} \mathrm{~S} / \mathrm{m}$

\begin{tabular}{|c|c|c|c|c|c|}
\hline \multirow{2}{*}{$\begin{array}{c}\text { Material } \\
\text { dimensions }\end{array}$} & \multirow{2}{*}{$\begin{array}{c}\text { Meas. } \\
\mathrm{f}_{\mathrm{r}}[\mathrm{GHz}]\end{array}$} & \multirow{2}{*}{$\begin{array}{c}\text { Meas. } \\
\mathrm{Q}\end{array}$} & $\begin{array}{c}\text { Data } \\
\text { sheet }\end{array}$ & This paper & NIST \\
\hline $\begin{array}{c}\mathbf{D 8 6 2 3} \\
\mathrm{a}=29.83 \mathrm{~mm} \\
\mathrm{~h}_{\mathrm{m}}=3.36 \mathrm{~mm}\end{array}$ & 2.09567 & 2819 & 75 & $75.09-\mathrm{j} \cdot 0.0020$ & 79.6 \\
\hline $\begin{array}{c}\text { D6 } \\
\mathrm{a}=29.83 \mathrm{~mm} \\
\mathrm{~h}_{\mathrm{m}}=5.98 \mathrm{~mm}\end{array}$ & 2.03163 & 3510 & 6.3 & $6.54-\mathrm{j} \cdot 0.0026$ & 6.59 \\
\hline
\end{tabular}

A. Values of $I_{m n}^{(s)}$ and $I_{m n}^{(c)}$ in (9)

Integrals $I_{m n}^{(s)}$ and $I_{m n}^{(c)}$ are:

$$
\begin{gathered}
I_{m n}^{(s)}=\int_{z=0}^{h} \cosh \left(\gamma_{n} z\right) \sin \left(2 \pi m \frac{z}{h}\right) d z= \\
=-\pi m h \operatorname{sinc}\left(\frac{n}{2}+m\right) \operatorname{sinc}\left(\frac{n}{2}-m\right) \\
I_{m n}^{(c)}=\int_{z=0}^{h} \cosh \left(\gamma_{n} z\right) \cos \left(2 \pi m \frac{z}{h}\right) d z= \\
=\frac{h}{2 \chi_{m}} \delta(n-2 m)
\end{gathered}
$$

and $\chi_{n}$ is defined as:

$$
\chi_{n}=\left\{\begin{array}{cc}
1 / 2, & m=0 \\
1, & m \neq 0
\end{array}\right.
$$

\section{B. Basis functions used in port 3}

The basis functions used for the series expansion at port 3 (see magnetic field in port 3 in (14)) and port 4 are based on a generalization of the Dini series expansion [49] as reported in [50].

The general expression for the series expansion of a function $f(r)$ is:

$$
f(r)=\sum_{m=0}^{\infty} \frac{c_{m}}{B\left(\mu_{m}\right)} \Phi_{v}\left(\mu_{m} r, \mu_{m} a\right), a \leq r \leq b
$$

where order $v$ is an arbitrary value and where the weights of the series expansion are:

$$
\begin{gathered}
c_{m}=\int_{r=a}^{b} r f(r) \Phi_{v}\left(\mu_{m} r, \mu_{m} a\right) d r \\
B\left(\mu_{m}\right)=\int_{r=a}^{b} r \Phi_{v}^{2}\left(\mu_{m} r, \mu_{m} a\right) d r
\end{gathered}
$$

The basis function $\Phi_{v}\left(\mu_{m} r, \mu_{m} a\right)$ is:

$$
\begin{gathered}
\Phi_{v}\left(\mu_{m} r, \mu_{m} a\right)=\mu_{m} h_{1} f_{1 v}\left(\mu_{m} r, \mu_{m} a\right)- \\
f_{2 v}\left(\mu_{m} r, \mu_{m} a\right) \\
f_{1 v}\left(\mu_{m} r, \mu_{m} a\right)=\frac{\pi \mu_{m} a}{2} \cdot \\
\cdot\left[\mathrm{Y}_{v}{ }^{\prime}\left(\mu_{m} a\right) \mathrm{J}_{v}\left(\mu_{m} r\right)-\mathrm{J}_{-v}{ }^{\prime}\left(\mu_{m} a\right) \cdot \mathrm{Y}_{v}\left(\mu_{m} r\right)\right] \\
f_{2 v}\left(\mu_{m} r, \mu_{m} a\right)=\frac{-\pi \mu_{m} a}{2} . \\
\cdot\left[\mathrm{Y}_{v}\left(\mu_{m} a\right) \mathrm{J}_{v}\left(\mu_{m} r\right)-\mathrm{J}_{v}{ }^{\prime}\left(\mu_{m} a\right) \mathrm{Y}_{v}\left(\mu_{m} r\right)\right]
\end{gathered}
$$

Then, following these definitions, the series expansion in (27) is true if: 


$$
\begin{aligned}
& \Phi_{v}\left(\mu_{m} r, \mu_{m} a\right)+\left.h_{1} \frac{\partial \Phi_{v}\left(\mu_{m} r, \mu_{m} a\right)}{\partial r}\right|_{r=a}=0 \\
& \Phi_{v}\left(\mu_{m} r, \mu_{m} a\right)+\left.h_{2} \frac{\partial \Phi_{v}\left(\mu_{m} r, \mu_{m} a\right)}{\partial r}\right|_{r=b}=0
\end{aligned}
$$

The first equation is always true (and can be easily proved) and the second one implies that, for a given $h_{l}$ and $h_{2}$ :

$$
\begin{gathered}
\mu_{m} h_{2}\left[\begin{array}{c}
\mu_{m} h_{1} f_{1 v}{ }^{\prime}\left(\mu_{m} b, \mu_{m} a\right)- \\
f_{2 v}{ }^{\prime}\left(\mu_{m} b, \mu_{m} a\right)
\end{array}\right]+ \\
{\left[\mu_{m} h_{1} f_{1 v}\left(\mu_{m} b, \mu_{m} a\right)-f_{2 v}\left(\mu_{m} b, \mu_{m} a\right)\right]=0}
\end{gathered}
$$

The zeros of this equation are the parameters $\mu_{m}$ used in the series expansion. In our case, we are using $v=1$ and $h_{l}=a$ and $h_{2}=b$, and then the basis function is:

$$
\begin{gathered}
\Phi_{1}\left(\mu_{m} r, \mu_{m} a\right)=\omega_{1 m}(r)=\frac{\pi \mu_{m}^{2} a^{2}}{2} . \\
{\left[\mathrm{J}_{1}\left(\mu_{m} r\right) \mathrm{Y}_{0}\left(\mu_{m} a\right)-\mathrm{J}_{0}\left(\mu_{m} a\right) \mathrm{Y}_{1}\left(\mu_{m} \cdot r\right)\right]}
\end{gathered}
$$

where the function $\omega_{1 m}(r)$ has been defined, and used in (14), and where $\mu_{m}$ are the zeros of:

$$
\begin{gathered}
\omega_{0 m}(b)=\frac{\pi \mu_{m}^{2} a^{2}}{2} \\
{\left[\mathrm{~J}_{0}\left(\mu_{m} b\right) \mathrm{Y}_{0}\left(\mu_{m} a\right)-\mathrm{J}_{0}\left(\mu_{m} a\right) \mathrm{Y}_{0}\left(\mu_{m} b\right)\right]=0}
\end{gathered}
$$

It is important to remark that, apart from the trivial zero $\mu_{0}=0$, the rest of the zeros are the cut-off wave numbers of $\mathrm{TM}_{0 \mathrm{~m}}$ modes in the coaxial waveguide.

Finally term $B\left(\mu_{m}\right)$, the normalization term in (28), is:

$$
B\left(\mu_{m}\right)=\left\{\begin{array}{c}
\frac{a^{4} \mu_{m}^{2}}{2} \ln \left(\frac{b}{a}\right), m=0 \\
\frac{a^{4} \mu_{m}^{2}}{2}\left[-1+\left(\frac{\mathrm{J}_{0}\left(\mu_{m} a\right)}{\mathrm{J}_{0}\left(\mu_{m} b\right)}\right)^{2}\right], m>0
\end{array}\right.
$$

and it is important to note the zero in the origin $\left(\mu_{m}=0, m=0\right)$, where function $\omega_{I m}(r)$ is:

$$
\left.\omega_{1 m}(r)\right|_{m=0}=\frac{a^{2} \mu_{m}}{r}
$$

where the coefficient $c_{m}, m=0$, in the series expansion is:

$$
c_{0}=a^{2} \mu_{m} \int_{r=a}^{b} f(r) d r
$$

Note that this case is the TEM mode.

\section{Normalization term $N_{q}^{(e 3)}$}

$N_{q}^{(e 3)}$ is a normalization term for the electric field $[51,52]$, and is calculated as:

$$
\begin{aligned}
& \int_{r=a}^{b} h_{q}^{(3)}(r) h_{m}^{(3)}(r) r d r= \\
& =\int_{r=a}^{b} \omega_{1 q}^{(3)}(r) N_{q}^{(e 3)} \omega_{1 m}^{(3)}(r) N_{m}^{(e 3)} r d r=\delta_{m q} \\
& N_{q}^{(e 3)}=\left\{\begin{array}{c}
\frac{1}{a^{2} \mu_{0} \sqrt{\ln (b / a)}}, q=0 \\
\frac{\sqrt{2}}{a^{2} \mu_{q} \sqrt{-1+\left(\frac{\mathrm{J}_{0}\left(\mu_{m} a\right)}{\mathrm{J}_{0}\left(\mu_{m} b\right)}\right)^{2}}}, q \neq 0
\end{array}\right.
\end{aligned}
$$

D. Value of integral $I_{q n}^{(\omega)}$ in (15)

Integral $I_{q n}^{(\omega)}$ is:

$$
\begin{gathered}
I_{q n}^{(\omega)}=\int_{r=a}^{b} f^{\prime}{ }_{0 n}(r) \cdot \omega_{1 q}^{(3)}(r) \cdot r \cdot d r= \\
\left\{\begin{array}{c}
\frac{-a \cdot k_{c 0 n}}{k_{c 0 n}^{2}-k_{c 0 q}^{2}} \cdot f_{0 n}(a) \cdot \omega_{1 q}^{(3)}(a), q>0 \\
\frac{-a^{2} \cdot f_{0 n}(a)}{k_{c 0 n}}, q=0
\end{array}\right.
\end{gathered}
$$

\section{ACKNOWLEDGMENT}

The author Peñarada-Foix thanks to the Conselleria de Educación of the Generalitat Valenciana for economic support to the stay in the U.S. (BEST/2010/210)

This work has been financed by the Ministry of Science and Innovation of Spain through the project MONIDIEL (TEC2008-04109)

\section{REFERENCES}

[1] Juan A. Monsoriu, Miguel V. Andrés, Anrique Silvestre, Albert Ferrando and Benito Gimeno, Analysis of Dielectric-Loaded Cavities Using an Orthonormal-Basis Method. IEEE Trans. on Microwave Theory and Techniques. vol. 50, no. 11, Nov. 2002, pp. 2545-2552.

[2] S. Charmond, C. P. Carry, C. P. and D. Bouvard, Densification and microstructure evolution of Y-Tetragonal Zirconia Polycrystal powder during direct and hybrid microwave sintering in a single-mode cavity. Journal of the European Ceramic Society. vol. 30, no. 6, 2010, pp. 1211-1221 (doi:10.1016/j.jeurceramsoc.2009.11.014).

[3] Thomas Baum, Lachlan Thompson and Kamran Ghorbani, Complex Dielectric Measurements of Forest Fire Ash at X-Band Frequencies. IEEE Geoscience And Remote Sensing Letters. vol. 8, no. 5, Sept. 2011, pp. 859-863.

[4] Slawomir Hausman, Lukasz Januszkiewicz, Marina Michalak, Tomasz Kacprzak and Izabella Krucinska, High Frequency Dielectric Permittivity of Nonwoven. FIBRES \& TEXTILES in Eastern Europe. vol. 14, no. 5, Jan./Dec. 2006, pp. 60-63.

[5] Tomohiro Oguchi, Munehiro Udagawa, Noriyuki Nanba, Masayuki Maki and Yasuhiro Ishimine, Measurements of Dielectric Constant of Volcanic Ash Erupted From Five Volcanoes in Japan. IEEE 
Transactions On Geoscience And Remote Sensing. vol. 47, no. 4, April 2009, pp. 1089-1096.

[6] Raphaël Renoud, Caroline Borderon and Hartmut W. Gundel, Measurement and Modeling of Dielectric Properties of $\mathrm{Pb}(\mathrm{Zr}, \mathrm{Ti}) \mathrm{O} 3$ Ferroelectric Thin Films. IEEE Transactions on Ultrasonics, Ferroelectrics and Frequency Control. vol. 58, no. 9, Sept. 2011, pp. 1975-1980.

[7] Mingwei Zhang, Jiwei Zhai and Xi Yao, Microwave dielectric properties of high dielectric tunable - low permittivity $\mathrm{Ba} 0.5 \mathrm{Sr} 0.5 \mathrm{TiO}-$ $\mathrm{Mg} 2(\mathrm{Ti} 0.95 \mathrm{Sn} 0.05) \mathrm{O} 4$ composite ceramics. Ceramics International. In Press, Corrected Proof, Available online 30 April 2011 (doi:10.1016/j.ceramint.2011.04.07).

[8] C.C. Khaw, K.B. Tan and C.K. Lee, High temperature dielectric properties of cubic bismuth zinc tantalate. Ceramics International. vol. 35, no. 4, May 2009, pp. 1473-1480.

[9] A. Chaouchi, S. d'Astorg and S. Marinel, Low sintering temperature of $(\mathrm{Zn} 0.65 \mathrm{Mg} 0.35) \mathrm{TiO} 3-\mathrm{xCaTiO} 3$-based dielectric with controlled temperature coefficient. Ceramics International. vol. 35, no. 5, July 2009, pp. 1985-1989.

[10] Denis L. Guerra, Silze P. Oliveira, Ricardo A.S. Silva, Emiliano M. Silva and Adriano C. Batista, Dielectric properties of organofunctionalized kaolinite clay and application in adsorption mercury cation. Ceramics International. In Press, Corrected Proof, Available online 5 October 2011 (doi:10.1016/j.ceramint.2011.09.062).

[11] Jerzy Krupka and Wociech Gwarek, Measurements and Modeling of Planar Metal Film Patterns Deposited on Dielectric Substrates. IEEE Microwave And Wireless Components Letters. vol. 19, no. 3, March 2009, pp. 134-136.

[12] Jerzy Krupka, Wojciech Gwarek, Norbert Kwietniewski and John G. Hartnett, Measurements of Planar Metal-Dielectric Structures Using Split-Post Dielectric Resonators. IEEE Transactions On Microwave Theory And Techniques. vol. 58, no. 12, Dec. 2010, pp. 3511-3518.

[13] James Baker-Jarvis, Michael Janezic and Donald Degroot, Highfrequency dielectric measurements. IEEE Instrumentation Measurement Magazine. vol. 13, no. 2, 2010, pp. 24-31.

[14] Udo Kaatze and Christof Hübner, Electromagnetic techniques for moisture content determination of materials. Meas. Sci. Technol. vol. 21, 2010, pp. 1-26. (doi:10.1088/0957-0233/21/8/082001)

[15] Udo Kaatze, Techniques for measuring the microwave dielectric properties of materials. Metrologia. vol. 47, 2010, pp. S91-S113.

[16] Jerzy Krupka, Frequency domain complex permittivity measurements at microwave frequencies. Meas. Sci. Tech. vol. 17, 2006, pp. R55-R70.

[17] J. Baker-Jarvis, M. D. Janezic, B. F. Riddle, R. T. Johnk, P. Kabos, C. L. Holloway, R. G. Geyer and C. A. Grosvenor, Measuring the permittivity and permeability of lossy materials: solids, liquids, metals, building materials and negative index materials. NIST Technical Note 1536, Feb. 2005.

[18] Felipe L. Penarada-Foix, Pedro J. Plaza-González, Beatriz García-Baños and Daniel Polo-Nieves, "A Non-destructive Method of Measuring the Dielectricand Magnetic Properties of Laminate Materials in Open Cavities". Proc. Of the IMS2004, Fort Worth, TX (USA) 2004, vol. 3, pp. 1821-1823.

[19] Michael D. Janezic and James Baker-Jarvis, "Full-Wave Analysis of a Split-Cylinder Resonator for Nondestructive Permittivity Measurements". IEEE Trans. Microwave Theory and Tech., vol. 47, No. 10, Oct. 1999, pp. 2014-2020.

[20] James Baker-Jarvis, Michael D. Janezic, Paul D. Domich and Richard G. Geyer. Analysis of an Open-Ended Coaxial Probe with Lift-Off for Nondestructive Testing, IEEE Trans. On Instrumentation and Measurement, vol. 43 No 5, Oct. 1994, pp. 711-718.

[21] A. Taflove, "Computational Electrodynamics: the Finite-Difference Time-Domain Method". Norwood, MA: Artech House, 1995.

[22] J. Volakis, "Finite Element Method for Electromagnetics", New York: IEEE Press, 1998.

[23] Alvin Wexler, Solution of Waveguide Discontinuities by Modal Analysis. IEEE Transactions On Microwave Theory And Techniques. vol. 15 , no. 9 , Sept. 1967 , pp. 508-517.

[24] H. Patzelt and F. Arndt, Double-Plane Steps in Rectangular Waveguides and their Application for Transformers, Irises, and Filters. IEEE Transactions On Microwave Theory And Techniques. vol. 30, no. 5, May 1982, pp. 771-776.

[25] G. Conciauro, M. Guglielmi and R. Sorrentino, "Advanced Modal Analysis". New York: Wiley, 2000.
[26] J.A. Ruiz-Cruz, J. Esteban and J.M. Rebollar, Efficient boundary contour mode-matching method of $\mathrm{H}$ - and E-plane junctions by fast Fourier transform algorithm. IEE Proc. Microw. Antenas Propag., vol. 150 , No. 5, October 2003, pp. 332-338.

[27] J. Gil, A.A. San Blas, C. Vicente, B. Gimeno, M. Bressan, V.E. Boria, G. Conciauro and M. Maestre, Full-Wave Analysis and Design of Dielectric-Loaded Waveguide Filters Using a State-Space IntegralEquation Method. IEEE Transactions on Microwave Theory and Techniques, vol. 57, No. 1, Jan. 2009, pp. 109-120.

[28] J. Gil, A.M. Perez, B. Gimeno, M. Bressan, V.E. Boria and G. Conciauro, Analysis of Cylindrical Dielectric Resonators in Rectangular Cavities Using a State-Space Integral-Equation Method. IEEE Microwave and Wireless Components Letters, vol. 16, No. 12, Dec. 2006, pp. 636-638.

[29] James Baker-Jarvis and Bill F. Riddle, Dielectric Measurements Using a Reentrant Cavity: Mode-Matching Analysis. NIST Technical Note 1384, Nov. 1996.

[30] R. Lech and L. Mazur, Analysis of Circular Cavity With Cylindrical Objects. IEEE Transactions On Microwave Theory And Techniques. vol. 55 , no. 10 , Oct. 2007, pp. 2115-2123.

[31] Weiguo Xi and Wayne R. Tinga, Field Analysis of New Coaxial Dielectrometer. IEEE Trans. on Microwave Theory and Techniques. vol. 40, no. 10, Oct. 1992, pp. 1927-1934.

[32] Jingliang Zheng and Ming Yu, Rigorous Mode-Matching Method of Circular to Off-Center Rectangular Side-Coupled Waveguide Junctions for Filter Applications. IEEE Trans. on Microwave Theory and Techniques. vol. 55, no. 11, Nov. 2007, pp. 2365-2373.

[33] Felipe L. Penaranda-Foix, "Application of the Generalized Circuital Analysis Theory to the Resolution of Electromagnetic Diffraction Problems" (in Spanish), Ph.D. dissertation, Universidad Politécnica de Valencia, Valencia, Spain, 2001.

[34] Felipe L. Penaranda-Foix and Miguel Ferrando-Bataller, "Scattering of Inhomogeneous Cylinders by Circuital Analysis". Microwave and Optical Technology Letters, Vol 39, N. 2, Oct. 2003, pp. 155-159.

[35] Felipe L. Penaranda-Foix, Jose M. Catala-Civera, Antoni J. Canos-Marin and Pedro J. Plaza-Gonzalez, "Solving Cylindrically-Shaped Waveguides Partially-Filled with Isotropic Materials by Modal Techniques", in Proc. of 11th. AMPERE 2007, Oradea (Romania), 2007, vol. 1, pp. 67-70.

[36] P. Arcioni, M. Bozzi, M. Bressan, G. Conciauro and L. Perregrini, Frequency/time-domain modelling of 3D waveguide structures by a BIRME approach. International Journal of Numerical Modelling: Electronic Networks, Devices and Fields. International Journal of Numerical Modelling: Electronic networks, Devices and Fields. vol. 15, no. 1, 2002, pp. 3-21.

[37] P. Soto, V. E. Boria, J. M. Catalá-Civera, N. Chouaib, N., M. Guglielmi and B. Gimeno, Analysis, Design, and Experimental Verification of Microwave Filters for Safety Issues in Open-Ended Waveguide Systems. IEEE Transactions On Microwave Theory And Techniques. vol. 48, no. 11, Nov. 2000, pp. 2133-2140.

[38] T. Sieverding and F. Arndt, Field theoretical cad of open or aperture matched T-junction coupled rectangular waveguide structures. IEEE Transactions On Microwave Theory And Techniques. vol. 40, no. 2, Feb. 1992, pp. 353-362.

[39] J. M. Rebollar, J. Esteban and J. E. Page, Fullwave analysis of three and port-port rectangular waveguide junctions. IEEE Transactions On Microwave Theory And Techniques. vol. 42, no. 2, Feb. 1994, pp. 256263.

[40] M. Ludovico, B. Piovano, G. Bertin, C. Zarba, L. Accatino and M. Mongiardo, CAD and optimization of compact ortho-mode transducers. IEEE Transactions On Microwave Theory And Techniques. vol. 47, no. 12, Dec. 1999, pp. 2479-2486.

[41] A. Alvarez, G. Connor and M. Guglielmi, New simple procedure for the computation of the multimode admittance or impedance matrix of planar waveguide junctions. IEEE Transactions On Microwave Theory And Techniques. vol. 44, no. 3, March 1996, pp. 413-418.

[42] H. Kawabata, H. Tanpo and Y. Kobayashi, Analysis and Experiments of a TM 010 Mode Cylindrical Cavity to Measure Accurate Complex Permittivity of Liquid. IEICE Trans. Electron. vol. E87-C, no. 5, May 2004, pp. 694-699.

[43] Hirokazu Kawabata, Yoshio Kobayashi and Syougo Kaneko, Analysis of Cylindrical Cavities to Measure Accurate Relative Permittivity and 
Permeability of Rod Samples. Proceedings of Asia-Pacific Microwave Conference 2010, pp. 1459-1462.

[44] Felipe L. Penaranda-Foix and Jose M. Catala-Civera, "Circuital analysis of cylindrical structures applied to the electromagnetic resolution of resonant cavities", Chapter 7 in Passive Microwave Components and Antennas, $1^{\text {st }}$ ed, Ed. IN-TECH, April 2010 (ISBN 978-953-307-083-4). Hardcopy and Online paper are available at webpage: http://sciyo.com/books/show/title/passive-microwave-components-andantennas.

[45] J.M. Rebollar and J.A. Encinar, Field Theory Analysis of MultiportMultidiscontinuity Structures: An application to Short-circuited E-plane Septum. IEE Proc. Part H, Microw. Antenas Propag., vol. 135, Pt. H, No. 1, February 1988,pp. 1-7.

[46] J. D. Wade and R. H. MacPhie, Conservation of complex power technique for waveguide junctions with finite wall conductivity. IEEE Trans. on Microwave Theory and Techniques, vol. 35, No. 4, April 1990, pp. 373-378.

[47] Jerzy Krupka and Janina Mazierska, Contactless Measurements of Resistivity of Semiconductor Wafers Employing Single-Post and SplitPost Dielectric-Resonator Techniques. IEEE Trans. on Instrumentation and Measurements. vol. 56, no. 5, Oct. 2007, pp. 1839-1844.

[48] C. A. Balanis, "Advanced Engineering Electromagnetics". John Wiley \& Sons, 1989.

[49] G. N. Watson, "A Treatise on the Theory of Bessel Funcions". Cambridge Mathematical Library, 1995.

[50] B. G. Korenev, "Bessel Functions and their Applications". Taylor and Francis, 2002.

[51] G. G. Gentili, Properties of TE-TM mode-matching techniques. IEEE Trans. on Microwave Theory and Techniques. vol. 39, no. 9, Sept. 1991, pp. 1669-1673.

[52] G. V. Eleftheriades, A. S. Omar and L. P. B. Katehi, Some Important Properties of Waveguide Junction Generalized Scattering Matrices in the Context of the Mode Matching Technique. IEEE Trans. on Microwave Theory and Techniques. vol. 42, no. 10, Oct. 1994, pp. 1896-1903.

[53] Robert E. Collin, "Foundations for Microwave Engineering". IEEE Press Classic Reissue, 2001.

[54] M. A. Leontovich, On the approximate boundary conditions for electromagnetic fields on the surface of well conducting bodies. Investigations of Propagation of Radio Waves, vol. B. A. Vvdensky, Ed. Moscow: Academy of Sciences USSR, pp. 5-20, 1948.

[55] T. B. Senior, Impedance boundary conditions for imperfectly conducting surfaces. Applied Science Research, vol. 8, pp. 418-436, 1960.

[56] R. F. Harrington, "Time-Harmonic Electromagnetic Fields", McGraw Hill, New York, 1961.

[57] Felipe L. Penaranda-Foix, Jose M. Catala-Civera, Antoni J. Canos-Marin and Beatriz Garcia-Banos, "Circuital analysis of a coaxial re-entrant cavity for performing dielectric measurement", in Proc. of the IMS2009, Boston, MA (USA) 2009, vol. 1 pp. 1309-1312.

[58] Weiguo Xi, Wayne R. Tinga, W. A. Geoffrey Voss and Bai Quiang Tian, New Results for Coaxial Re-Entrant Cavity with Partially Filled Gap. IEEE Trans. on Microwave Theory and Techniques. vol. 40, no. 4, April 1992, pp. 747-753.

[59] Marek Jaworski, On the Resonant Frequency of a Re-entrant Cylindrical Cavity. IEEE Trans. on Microwave Theory and Techniques. vol. 26, no. 4, April 1978, pp. 256-260.

[60] A. G. Williamson, The resonant frequency and tuning characteristics of a narrow-gap Re-entrant Cavity. IEEE Trans. on Microwave Theory and Techniques. vol. 24, no. 4, April 1976, pp. 182-187.

[61] Richard G. Carter, Jinjun Feng and Ulrich Becker, Calculation of the Properties of Reentrant Cylindrical Cavity Resonators. IEEE Trans. On Microwave Theory and Techniques, vol. 55, No. 12, Dec. 2007, pp. 2531-2538.

[62] Hyo J. Eom, Young C. Noh and Jong K. Park, Scattering Analysis of a Coaxial Line Terminated by a Gap. IEEE Microwave and Guided Wave Letters, Vol. 8, No. 6, June 1998, pp. 218-219.

[63] Andrew R. Weily and Ananda S. Mohan, Rotationally Symmetric FDTD for Wideband Performance Prediction of TM01 DR Filters. International Journal of $R F$ and Microwave Computer-Aided Engineering. vol. 12, no. 3, 2002, pp. 259-271.

[64] Chi Wang, Kawthar A. Zaki, Ali E. Atia and Tim G. Dolan, Dielectric Combline Resonators and Filters. IEEE Trans. on Microwave Theory and Techniques. vol. 46, no. 12, Dec. 1998, pp. 2501-2506.
[65] Kawthar A. Zaki and Chunming Chen, New Results in DielectricLoaded Resonators. IEEE Trans. on Microwave Theory and Techniques. vol. 34, no. 7, July 1986, pp. 815-824.

[66] Jeffrey C. Lagarias, James A. Reeds, Margaret H. Wright and Paul E. Wright, Convergence Properties of the Nelder-Mead Simplex Method in Low Dimensions. SIAM Journal of Optimization, 9(1), 1998, p.112-147.

[67] A. J. Canos, J. M. Catala-Civera, F. L. Penaranda-Foix and E. ReyesDavo, A novel technique for deembedding the unloaded resonance frequency from measurements of microwave cavities. IEEE Transactions on Microwave Theory and Techniques. vol. 54, no. 8, Aug. 2006, pp. 3407-3416. 